Goldschmidt 2021 Abstract

https://doi.org/10.7185/gold2021.3197

\section{Depth profile of Re-Os concentrations and isotope ratios in the \\ hydrothermally altered clay obtained from Brothers volcano hydrothermal field during the IODP Expedition 376}

hydrothermal field.

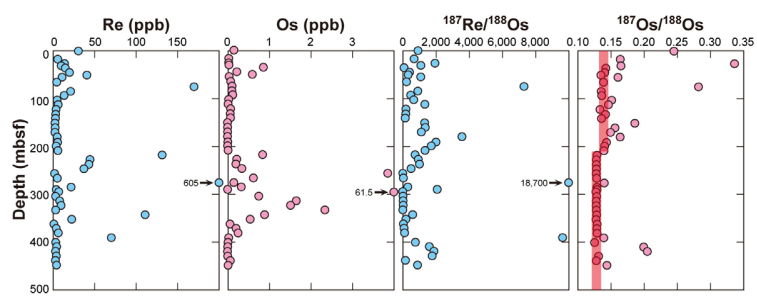

\author{
TATSUO NOZAKI ${ }^{1}$, MIZUKI ISHIDA $^{2}$, YUTARO \\ TAKAYA $^{3}$, QING CHANG ${ }^{4}$, JUN-ICHI KIMURA ${ }^{4}$ AND \\ YASUHIRO KATO ${ }^{5}$
}

${ }^{1}$ Submarine Resources Research Center, Research Institute for Marine Resources Utilization, Japan Agency for Marine-Earth Science and Technology

${ }^{2}$ Univ. of Tokyo

${ }^{3}$ Waseda University

${ }^{4}$ JAMSTEC

${ }^{5}$ Frontier Research Center for Energy and Resources, School of Engineering, The University of Tokyo

Presenting Author: nozaki@jamstec.go.jp

Os isotope systematics in the Earth's surface is similar to that of the $\mathrm{Sr}$ isotope, but the Os isotope ratio $\left({ }^{187} \mathrm{Os} /{ }^{188} \mathrm{Os}\right)$ between modern seawater $(\sim 1.06)$ and hydrothermal fluid $(\sim 0.13)$ is different in one order of magnitude. Thus, ${ }^{187} \mathrm{Os} /{ }^{188} \mathrm{Os}$ can be used as a sensitive tracer of the subseafloor mixing process between seawater and hydrothermal fluid. Here, we report a depth profile of Re-Os concentrations and isotope ratios in hydrothermally altered clay at Site U1530 (Hole U1530A) of Brothers volcano hydrothermal filed in the Kermadec arc, which was drilled during the IODP Expedition 376 (Fig. 1).

Re and Os concentrations of drill cores at Site U1530 (Hole $\mathrm{U} 1530 \mathrm{~A})$ are ranging from 0.58 to $605 \mathrm{ppb}$ and $0.0062(6.19 \mathrm{ppt})$ to $61.5 \mathrm{ppb} .{ }^{187} \mathrm{Re} /{ }^{188} \mathrm{Os}$ and ${ }^{187} \mathrm{Os} /{ }^{188} \mathrm{Os}$ have ranges from 0.50 to 18,700 and 0.126 to 0.336 , respectively. ${ }^{187} \mathrm{Os} /{ }^{188} \mathrm{Os}$ of altered clay is typically around 0.13 to 0.14 and there are some positive anomalies which were produced by two mechanisms; (1) mixing of seawater and hydrothermal fluid associated with high $\mathrm{Re}$ concentration and abundant occurrence of sulfide and/or sulfate minerals, and (2) seawater ingress having radiogenic ${ }^{187} \mathrm{Os} /{ }^{188} \mathrm{Os}$ corresponding to the relatively high chlorite abundance and high porosity interval at Hole U1530A, without any conspicuous ReOs enrichments and sulfide/sulfate mineralization.

Except for some positive anomalies, ${ }^{187} \mathrm{Os} /{ }^{188} \mathrm{Os}$ of altered clay is $\sim 0.14$ above $215 \mathrm{mbsf}$. However, below $215 \mathrm{mbsf},{ }^{187} \mathrm{Os} /{ }^{188} \mathrm{Os}$ values are quite constant of $\sim 0.128$ with an abnormal Os enrichment up to $61.5 \mathrm{ppb}$. This maximum Os concentration of $61.5 \mathrm{ppb}$ is 2,000 times higher than that of average upper continental crust $(\sim 31 \mathrm{ppt})$ and 15 times higher than typical ultramafic rock ( $\sim 4 \mathrm{ppb})$. The abnormal Os enrichment was only observed at the intercalated layer of alteration types II and V. Since the alteration type $\mathrm{V}$ is characterized by occurrences of pyrophyllite, diaspore and zunyite which are produced only under the acidic condition, the abnormal Os enrichment was plausibly induced by the volcanic gas input and Os gas mobilization as an $\mathrm{OsO}_{4}$ molecule. Our result is the first report of the volcanic gas input detected by using the Os isotope at the 